Supporting Information

\title{
Biogenic Quantum Dots for Sensitive, Label-free Detection of Mercury Ions
}

Li-Jiao Tian, ${ }^{\dagger}$ Yuan Min,${ }^{\dagger}$ Xue-Meng Wang,,$^{\dagger}$ Jie-Jie Chen, ${ }^{\dagger}$ Wen-Wei Li, ${ }^{*}, \dagger$ Jing-Yuan Ma, ${ }^{\ddagger}$ Han-Qing $\mathrm{Yu}^{\dagger}$

$\uparrow$ Department of Applied Chemistry, University of Science and Technology of

China, Hefei, 230026, China

‡ Shanghai Synchrotron Radiation Facility, Shanghai Institute of Applied

Physics, Chinese Academy of Sciences, Shanghai 201204, China

\section{Corresponding Author}

*E-mail: wwli@ustc.edu.cn 
Table S1. Binding energy of ligands with $\mathrm{Cd}^{2+}$ or $\mathrm{Hg}^{2+}$

\begin{tabular}{|c|c|c|c|}
\hline Ligand-ion & $\Delta G(\mathrm{eV})$ & Ligand - ion & $\Delta G(\mathrm{eV})$ \\
\hline $\mathrm{Sec}-\mathrm{Cd}^{2+}$ & -3.743 & $\mathrm{Sec}-\mathrm{Hg}^{2+}$ & -6.624 \\
\hline $2 \mathrm{Sec}-\mathrm{Cd}^{2+}$ & -4.588 & $2 \mathrm{Sec}-\mathrm{Hg}^{2+}$ & -7.718 \\
\hline $\mathrm{GSSeH}-\mathrm{Cd}^{2+}$ & -4.205 & GSSeH-Hg ${ }^{2+}$ & -7.576 \\
\hline $2 \mathrm{GSSeH}-\mathrm{Cd}^{2+}$ & -4.674 & $2 \mathrm{GSSeH}-\mathrm{Hg}^{2+}$ & -7.966 \\
\hline
\end{tabular}

Gibbs free energy change $(\Delta G)$ for the procedure of selenocysteine (Sec) and Se-glutathione (GSSeH) binding with $\mathrm{Cd}^{2+}$ and $\mathrm{Hg}^{2+}$ at room temperature. 
Table S2. Comparison among the different $\mathrm{Hg}^{2+}$ detection methods

\begin{tabular}{|c|c|c|c|c|c|c|}
\hline Fluorescent probe & Label molecule & $\begin{array}{l}\text { Reaction } \\
\text { time (min) }\end{array}$ & $\begin{array}{l}\text { LOD } \\
(\mathrm{nM})\end{array}$ & $\begin{array}{l}\text { Linear range } \\
\text { (nM) }\end{array}$ & Detection mechanism & Ref. \\
\hline $\begin{array}{c}3 \text { Mercaptoisobutyric acid- } \\
\text { CdTe QDs }\end{array}$ & $\begin{array}{l}3 \text { Mercaptoisobutyric } \\
\text { acid }\end{array}$ & $\mathrm{NM}^{\mathrm{a})}$ & 1.5 & $1.5-100$ & $\begin{array}{l}\text { QDs aggregation and } \\
\text { electron transfer }\end{array}$ & 1 \\
\hline Terpyridine-based test strip & Terpyridine & $\mathrm{NM}^{\mathrm{a})}$ & 690 & $0-10000$ & $\begin{array}{l}\text { Photoinduced electron } \\
\text { transfer }\end{array}$ & 2 \\
\hline DNA-magnetoresistance & DNA & 10 & 10 & $10-10000$ & $\begin{array}{l}\text { Bound superparamgnetic } \\
\text { magnetic nanoparticles }\end{array}$ & 3 \\
\hline QDs-MMS-Rh6G & $\begin{array}{c}\text { Rhodamine } \\
\text { 6G-deprived receptor }\end{array}$ & $\mathrm{NM}^{\mathrm{a})}$ & 2.5 & $7-900$ & $\mathrm{NM}^{\mathrm{a})}$ & 4 \\
\hline $\mathrm{Au} / \mathrm{Fe}_{3} \mathrm{O}_{4} / \mathrm{MoS}_{2} \mathrm{CAs}$ & $\mathrm{NM}^{\mathrm{a})}$ & 30 & $\begin{array}{c}3.27 \\
9\end{array}$ & $1000-14000$ & $\mathrm{NM}^{\mathrm{a})}$ & 5 \\
\hline Ag NPs & Oligonucleotides & 10 & 2.6 & $10-8000$ & $\mathrm{Ag} / \mathrm{Hg}$ amalgam & 6 \\
\hline QDs/DNA/Au NPs & DNA & 10 & 2 & $2-60$ & Surface energy transfer & 7 \\
\hline $\mathrm{Au}$ NPs & Cysteine & $\mathrm{NM}^{\mathrm{a})}$ & 100 & $0-2000$ & Aggregation & 8 \\
\hline Bio-QDs & None & 15 & 1.5 & $\begin{array}{c}1.5-100 \\
100-1000\end{array}$ & $\begin{array}{l}\text { Chemical substitution \& } \\
\text { electrostatic interaction }\end{array}$ & $\begin{array}{l}\text { This } \\
\text { work }\end{array}$ \\
\hline
\end{tabular}

a) Not mentioned in the article 


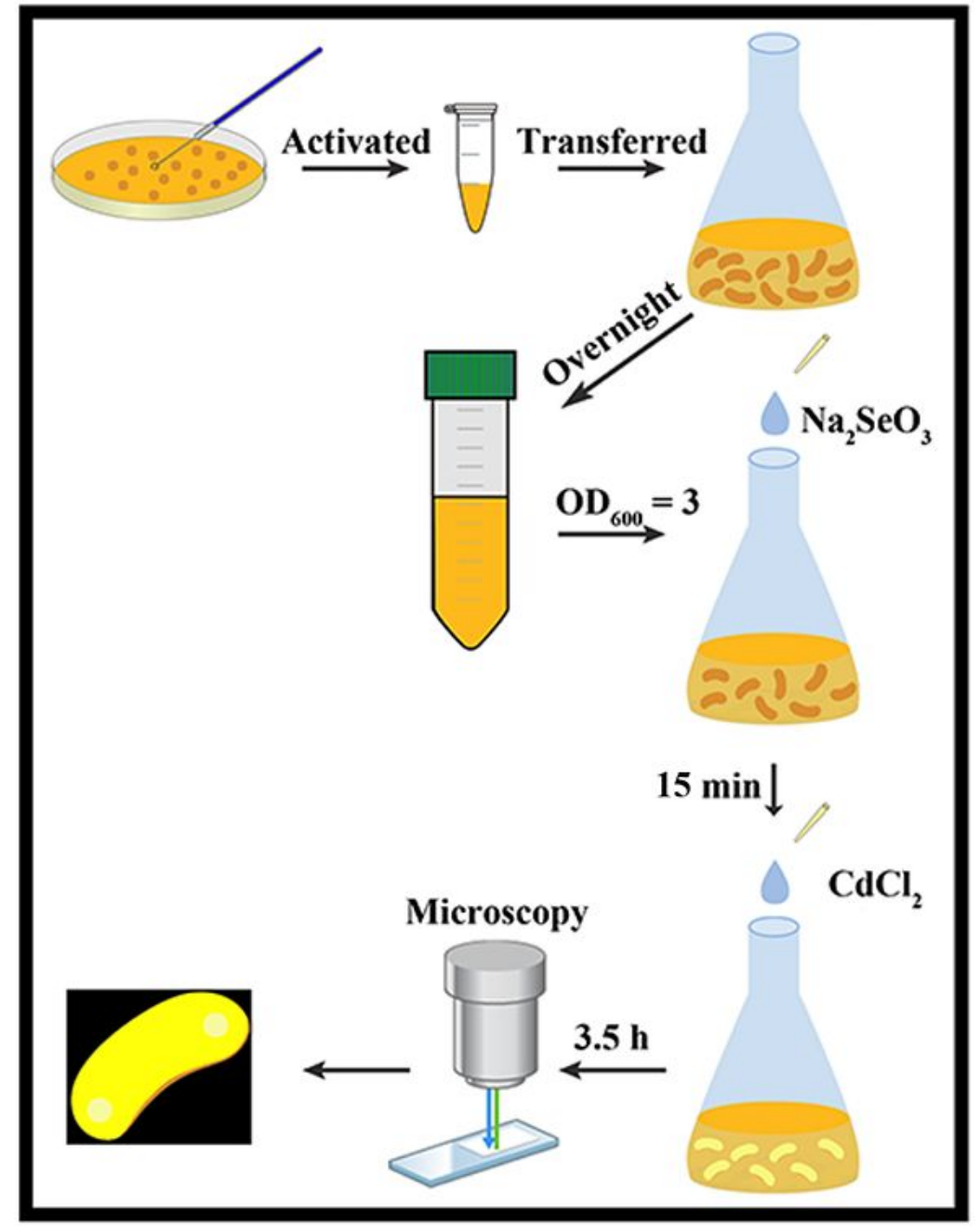

Figure S1. Procedures of E. coli cultivation for Bio-QDs synthesis. 

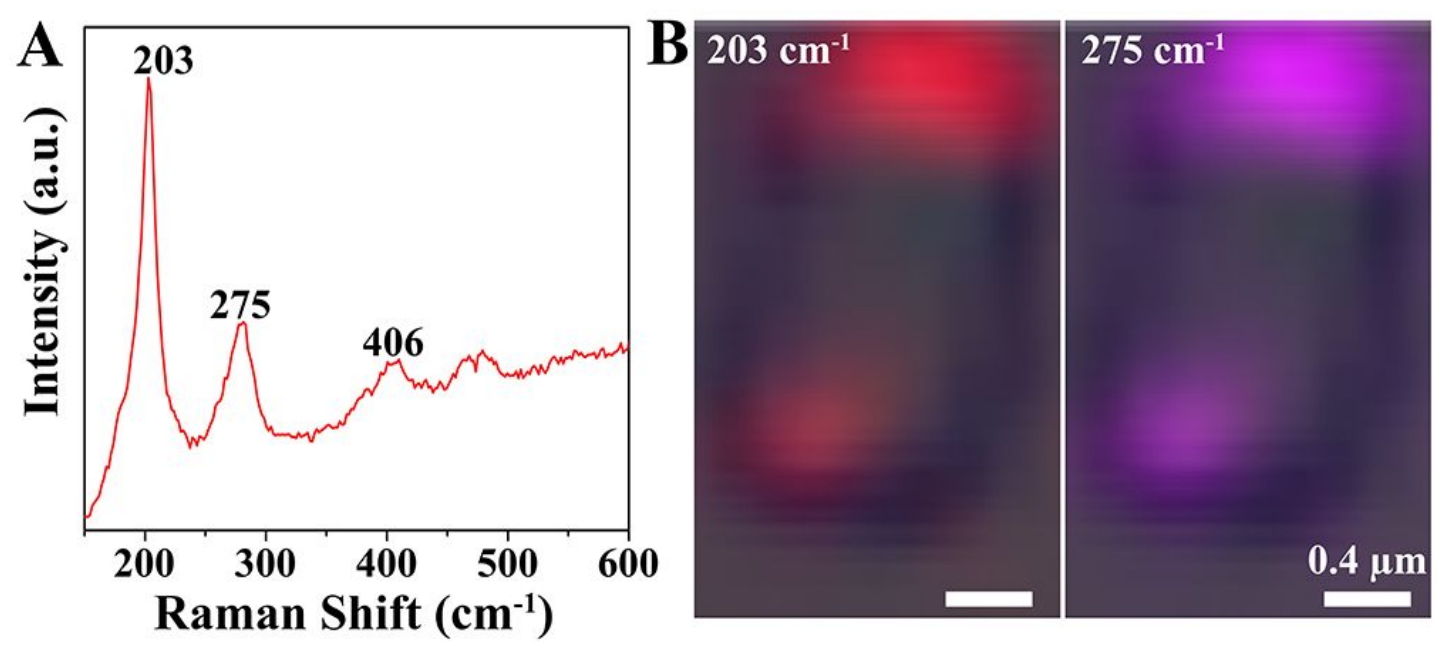

Figure S2. (A) In-situ Raman spectra of cell suspension after 4-h incubation in a medium containing $\mathrm{Na}_{2} \mathrm{SeO}_{3}(1 \mathrm{mM})$ and $\mathrm{CdCl}_{2}(6 \mathrm{mM})$. (B) Combined image of Raman mapping and bright-field microscopy image excited at $532 \mathrm{~nm}$. Raman mapping was recoded at $203 \mathrm{~cm}^{-1}$ (characteristic peak of Cd-Se) and $275 \mathrm{~cm}^{-1}$ (characteristic peak of Cd-S). 

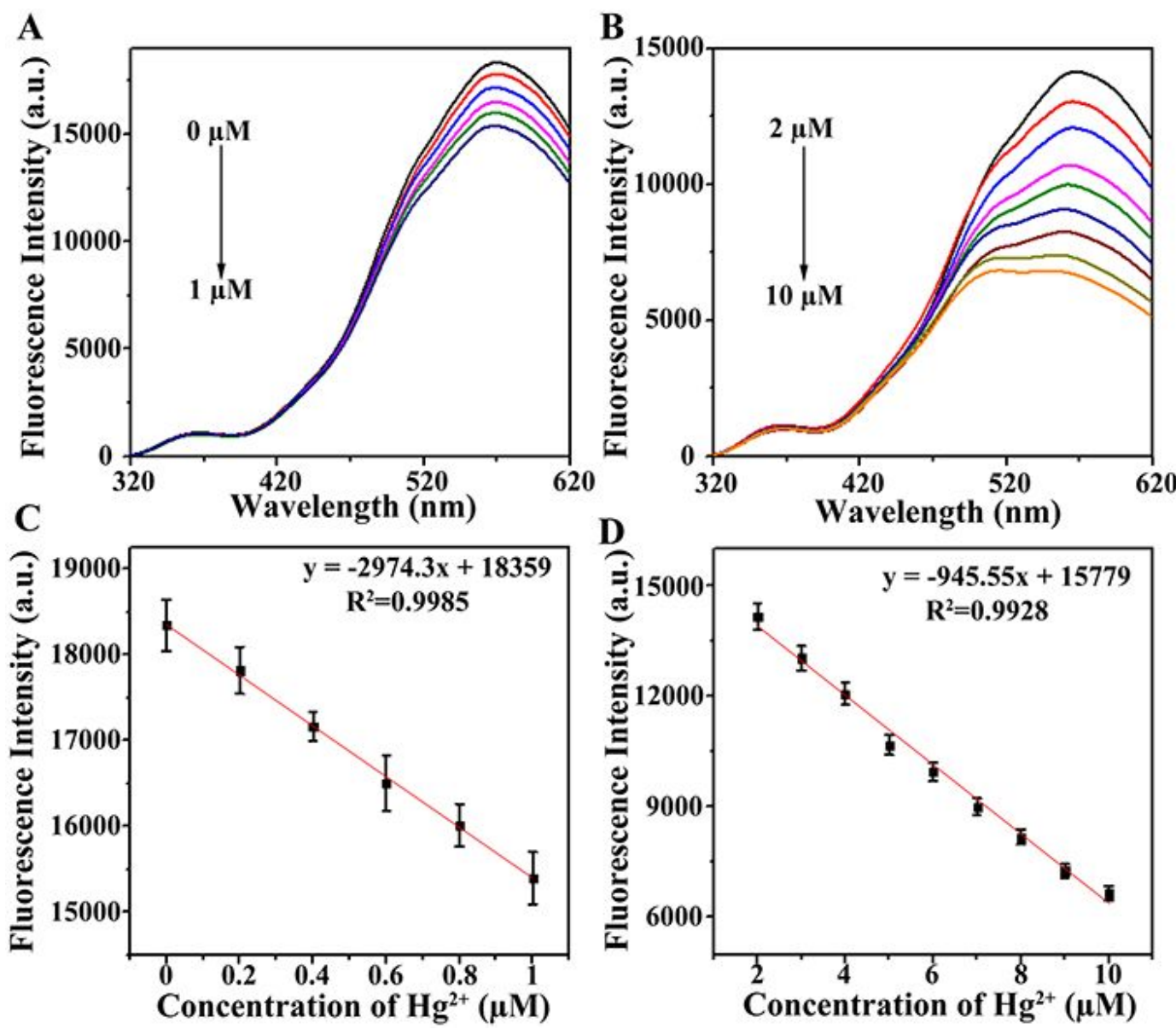

Figure S3. Fluorescence intensities of Bio-QDs stock solution in response to different $\mathrm{Hg}^{2+}$ concentrations. (A) Fluorescence emission spectra of the Bio-QDs upon $\mathrm{Hg}^{2+}$ addition at (A) low concentration range $\left(\mathrm{Hg}^{2+}\right.$ concentrations from top to bottom: $\left.0,0.2,0.4,0.6,0.8,1 \mu \mathrm{M}\right)$ and (B) high concentration range ( $\mathrm{Hg}^{2+}$ concentrations from top to bottom: $2,3,4,5,6,7,8,9$, $10 \mu \mathrm{M})$. Linear relationship between the fluorescence intensity and $\mathrm{Hg}^{2+}$ concentration at $(\mathrm{C})$ low concentration range and (D) high concentration range. 


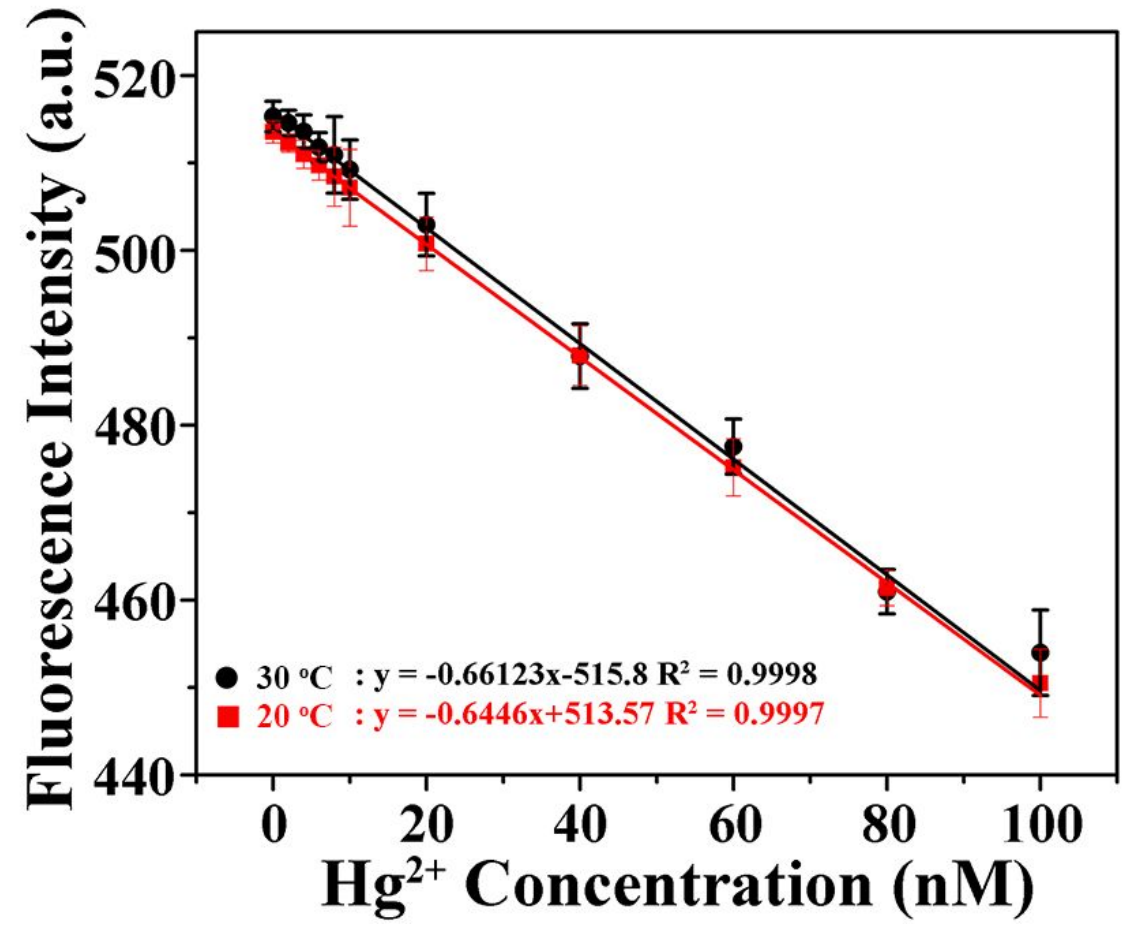

Fig. S4 Linear correlation between the fluorescence intensity of Bio-QDs and $\mathrm{Hg}^{2+}$ concentration obtained on different dates and with different cuvettes. The black and red colored lines refer to data collected in summe and winter, respectively. 


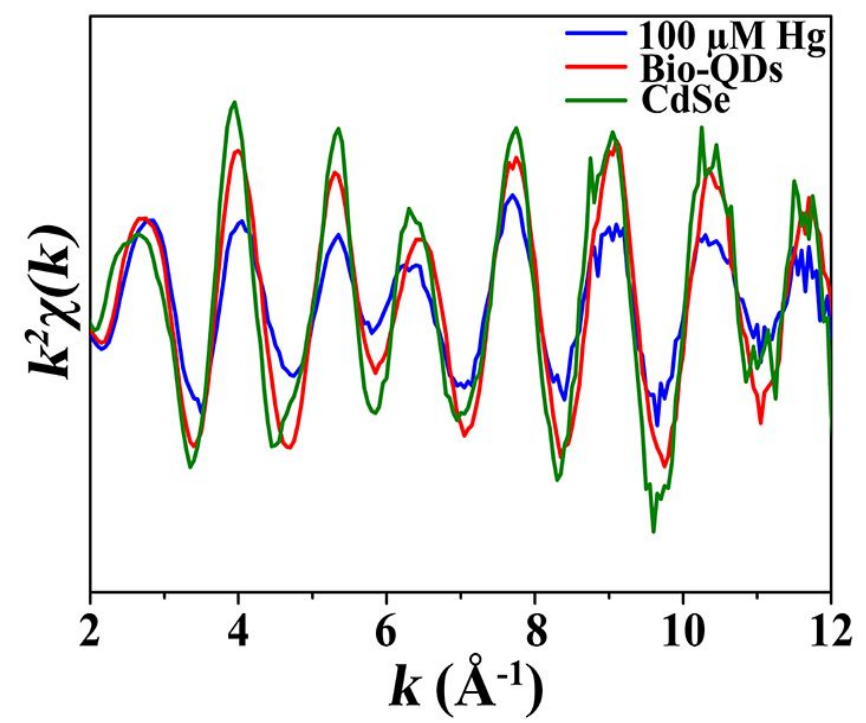

Figure S5. Se $K$-edge EXAFS analyses of the purified samples and CdSe standard in $k$ space. 


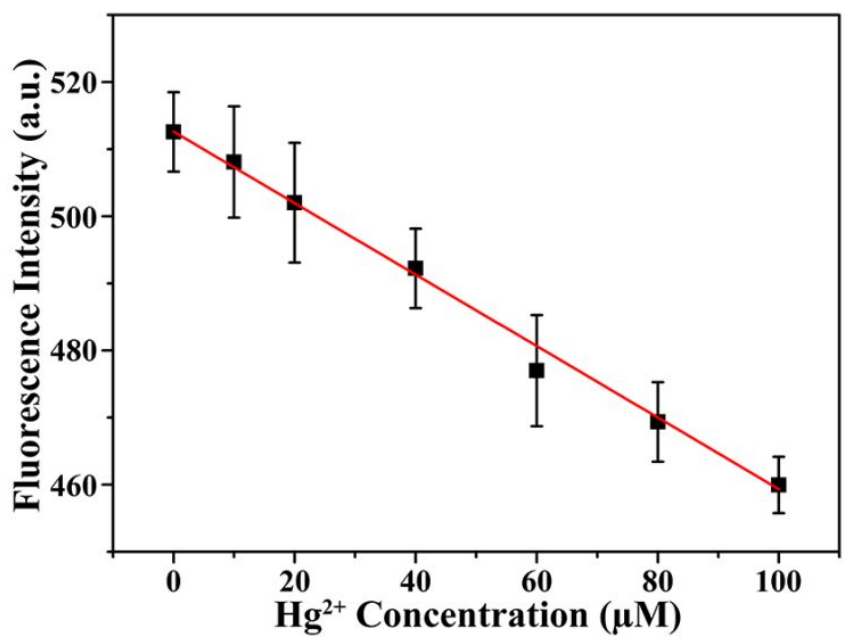

Figure S6. Fluorescence intensity of Bio-QDs in response to $\mathrm{Hg}^{2+}$ concentrations in tap water. Standard $\mathrm{Hg}^{2+}$ was spiked at different concentrations (0, 10, 20, 40, 60, 80, and $\left.100 \mathrm{nM}\right)$. 


\section{References}

1. Choudhary, Y. S.; Nageswaran, G., Branched mercapto acid capped CdTe quantum dots as fluorescence probes for $\mathrm{Hg}^{2+}$ detection. Sensing and Bio-Sensing Research 2019, 23, 100278.

2. Wang, J.; Rao, Q.; Wang, H.; Zhang, Q.; Liu, G.; Wu, Z.; Yu, J.; Zhu, X.; Tian, Y.; Zhou, H., A terpyridine-based test strip for the detection of $\mathrm{Hg}^{2+}$ in various water samples and drinks. Anal. Methods 2019, 11, 227-231.

3. Wang, W.; Wang, Y.; Tu, L.; Klein, T.; Feng, Y.; Li, Q.; Wang, J. P., Magnetic detection of mercuric ion using giant magnetoresistance-based biosensing system. Anal. Chem. 2014, $86,3712-3716$.

4. Wang, Y.; Tang, M.; Shen, H.; Che, G.; Qiao, Y.; Liu, B.; Wang, L., Recyclable multifunctional magnetic mesoporous silica nanocomposite for ratiometric detection, rapid adsorption, and efficient removal of $\mathrm{Hg}(\mathrm{II})$. ACS Sustain. Chem. Eng. 2018, 6, 1744-1752.

5. Zhi, L.; Zuo, W.; Chen, F.; Wang, B., 3D $\mathrm{MoS}_{2}$ composition aerogels as chemosensors and adsorbents for colorimetric detection and high-capacity adsorption of $\mathrm{Hg}^{2+}$. ACS Sustain. Chem. Eng. 2016, 4, 3398-3408.

6. Deng, L.; Ouyang, X.; Jin, J.; Ma, C.; Jiang, Y.; Zheng, J.; Li, J.; Li, Y.; Tan, W.; Yang, R., Exploiting the higher specificity of silver amalgamation: selective detection of mercury(II) by forming Ag/Hg amalgam. Anal. Chem. 2013, 85, 8594-8600.

7. Li, M.; Wang, Q.; Shi, X.; Hornak, L. A.; Wu, N., Detection of mercury(II) by quantum dot/DNA/gold nanoparticle ensemble based nanosensor via nanometal surface energy transfer. Anal. Chem. 2011, 83, 7061-7065.

8. Chai, F.; Wang, C.; Wang, T.; Ma, Z.; Su, Z., L-cysteine functionalized gold nanoparticles for the colorimetric detection of $\mathrm{Hg}^{2+}$ induced by ultraviolet light. Nanotechnology 2010, 21, 025501. 